\title{
ESQUEMA: UM GÊNERO FACILITADOR NA RECEPÇÃO E CONSTRUÇÃO TEXTUAL NA UNIVERSIDADE
}

\author{
Diana Guimarães ${ }^{1}$ \\ Geisiane Nunes ${ }^{2}$ \\ Regina Pereira ${ }^{3}$
}

\begin{abstract}
Resumo: O presente trabalho é fruto da oficina sobre esquema desenvolvida no V Workshop de Letramento Acadêmico, em 2017, na Universidade Federal da Paraíba, realizado pelo grupo de pesquisa Ateliê de Trabalhos Acadêmicos. O objetivo principal deste estudo é discutir sobre o gênero esquema como facilitador na recepção e na construção textual de outros gêneros no âmbito da universidade. O corpus é formado por esquemas de leitura e por esquemas para a produção futura de outro texto. Partimos da noção de gênero como constructo sócio histórico, considerado produto das atividades sociais de linguagem, e subsidiamos nossa análise pelos aportes teóricos do Interacionismo Sociodiscursivo, em relação aos parâmetros do contexto físico e sociossubjetivo de produção (BRONCKART, 1999).
\end{abstract}

Palavras-chave: Esquema. Escrita acadêmica. Gênero textual. Interacionismo Sociodiscursivo.

\begin{abstract}
This paper is result of a workshop about scheme organized at the V Academic Literacy Workshop, in 2017, at the Federal University of Paraíba, conducted by the Atelier of Academic Works research group. The main objective of this study is to discuss about the genre scheme as a facilitator in the reception and textual construction of other genres within the university. The corpus is formed by readings schemes and schemes for the future production of another text. We start from the notion of gender as a socio-historical construct, considered a product of social activities of language, and we subsidize our analysis by the theoretical contributions of Sociodiscursive Interactionism, in relation to the parameters of the physical and socio-subjective context of production (BRONCKART, 1999).
\end{abstract}

Keywords: Scheme. Academic writing. Textual genre. Sociodiscursive Interactionism.

\section{Introdução}

O grupo de pesquisa Ateliê de Textos Acadêmicos (ATA) surgiu em 2012 e é coordenado pela Profa. Dra. Regina Celi Mendes Pereira da Silva. No final de 2015, passou a fazer parte da Cátedra UNESCO de Leitura e Escritura da América Latina. O principal objetivo do grupo é investigar o processo de elaboração dos gêneros acadêmicos em conexão com diferentes áreas de conhecimento. Dessa forma, o ATA atua em dois sentidos: um direcionado para os processos de didatização da escrita acadêmica em disciplinas de Português Instrumental, Pesquisa Aplicada ao Ensino de Língua Portuguesa, Metodologia Científica e Leitura e Produção de Textos I; e outro dirigido para a análise dos parâmetros de produção e da arquitetura textual, na perspectiva do Interacionismo Sociodiscursivo (ISD), de artigos publicados em periódicos representativos de diversas áreas (PEREIRA; LEITÃO, 2017).

Durante esses anos de existência, os integrantes do ATA se mobilizaram na organização de vários eventos, realizados na Universidade Federal da Paraíba (UFPB), dentre eles o V Workshop de Letramento Acadêmico: A Didatização dos Gêneros Acadêmicos em Diferentes Áreas do Conhecimento, em agosto de 2017, o qual contou com duas oficinas:

\footnotetext{
${ }^{1}$ Mestre em Linguagem e Ensino pela Universidade Federal da Paraíba. E-mail: diana.rguimaraes@gmail.com.

2 Especialista em Estudos Linguísticos e Literários pela Universidade Estadual da Paraíba. E-mail: geisiane2008@gmail.com.

Professora Doutora em Linguística pela Universidade Federal de Pernambuco. E-mail: reginacmps@gmail.com.
} 
"Oficina 1 - Relatório: o que se faz no relatório além de relatar?" e "Oficina 2 - Esquema: um gênero facilitador?". E foi a partir da segunda oficina que surgiu a ideia do presente trabalho, em consonância com os objetivos do ATA, ou seja, promover e divulgar práticas de letramento acadêmico como forma de democratizar as competências de leitura e de escrita no contexto universitário.

Nesse sentido, o objetivo principal deste estudo é discutir sobre o gênero esquema como facilitador na recepção e na construção textual de outros gêneros no âmbito da universidade. Este trabalho também visa refletir sobre a funcionalidade do esquema no universo acadêmico, bem como reconhecer suas características linguístico-textuais e normativas, além de apresentar seus diversos tipos, conforme interesse de leitura e produção. O corpus é formado por 19 esquemas produzidos pelos participantes da oficina 2, sendo 16 esquemas de leitura, cujo texto-fonte é o resumo de um relatório de pesquisa, e 3 esquemas elaborados para a produção futura de um relatório.

Partindo, assim, da noção de gênero como constructo sócio -histórico, considerado produto das atividades sociais de linguagem (BRONCKART, 1999), neste artigo apresentaremos a conceitualização de esquema como gênero textual, além de sua classificação e funcionalidade, e mostraremos como produzir um esquema, mais especificamente no contexto acadêmico, além de relacioná-lo com outros gêneros. A análise dos dados será subsidiada pelos aportes teóricos do ISD, em relação aos parâmetros do contexto físico e sociossubjetivo de produção (BRONCKART, 1999).

\section{0 gênero textual esquema: características, funcionalidade e classificação}

Falar de gênero textual (ou gênero do discurso) remete, necessariamente, às contribuições teóricas de Mikhail Bakhtin sobre o tema, nas quais o ISD se fundamenta. Para esse autor, "Todas as esferas da atividade humana, por mais variadas que sejam, estão sempre relacionadas com a utilização da língua" e esta "[...] efetua-se em forma de enunciados (orais e escritos), concretos e únicos [...]" (BAKHTIN, 2000, p. 279). As funções - científica, técnica, ideológica, oficial, cotidiana - e as condições específicas para cada uma dessas esferas geram gêneros do discurso, ou seja, "tipos relativamente estáveis de enunciados" (BAKHTIN, 2000, p. 279), do ponto de vista de seu conteúdo temático, seu estilo verbal e sua construção composicional.

$\mathrm{Na}$ perspectiva do ISD, a atividade de linguagem se organiza em discursos ou em textos e, devido à "diversificação das atividades não verbais com as quais esses textos estão em interação, eles mesmos diversificam-se em gêneros" (BRONCKART, 1999, p. 35), ou seja, os gêneros textuais são as "formas variadas de "discursos"” (p. 37). Uma vez que "o texto é a unidade comunicativa de nível superior” (BRONCKART, 1999, p. 137), ele abrange, assim, toda comunicação verbal, seja esta escrita ou oral (gêneros primários e secundários ). Toda comunicação verbal, por sua vez, organiza-se em gêneros textuais , os quais são constructos sócio -históricos, por isso dinâmicos, que se (re)constroem de acordo com as necessidades do uso social; assim, os gêneros são considerados produtos das atividades sociais de linguagem.

Nesse sentido, observamos que, na universidade, com o intuito de dar conta do excesso de leitura e de produção textual, é importante que o estudante encontre formas para otimizar seu tempo e, assim, realizar, em período hábil, as atividades agendadas. Não por acaso, uma possibilidade de registrar linguisticamente o conteúdo de um texto lido é a partir da produção do gênero esquema. Na vida acadêmica, o estudante está, frequentemente, esquematizando as suas ações, seja como estratégias para sinalizar o que deverá ser 
mencionado em uma exposição oral, seja como estratégias de estudo para uma avaliação, por exemplo.

Sobre isso, Pereira e Silva (2007, p. 757) definem o esquema como

um gênero textual de meio de produção gráfica que tem como função sóciocomunicativa apresentar de forma sintética e de rápido reconhecimento as principais partes de um conteúdo ou assunto lido. Por ser um instrumento de estudo do texto, o esquema de leitura é bastante utilizado pelos interactantes dos domínios acadêmico e escolar.

Se considerarmos esse gênero como um instrumento por meio do qual se podem sumarizar as principais partes do conteúdo de um texto lido, fica mais fácil entendê-lo e utilizá-lo em atividades acadêmicas. O esquema antecede outros gêneros - a exemplo do resumo e da resenha - e pode ser produzido, como dito, para sintetizar as ideias centrais de um texto ou assunto lido, organizar sistematicamente uma apresentação oral e esboçar o esqueleto de um texto a ser redigido.

O esquema compartilha, assim, características com outros gêneros acadêmicos e escolares, tais como anotação de aula, roteiro, fichamento e resumo, entretanto, possui também as suas diferenças. Por exemplo, enquanto o esquema se limita a registrar pontos de um texto escrito, a anotação abarca aspectos mais gerais de uma aula que não estão necessariamente relacionados à escrita (PEREIRA; SILVA, 2007). Uma semelhança entre o esquema, a anotação de aula e o roteiro está na compreensão das informações por parte de um leitor estranho à produção desses gêneros, uma vez que, para esse entendimento acontecer, é necessária uma contextualização maior, diferentemente do que ocorre com o fichamento e o resumo. Estes conseguem envolver mais informações do que os outros, os quais, principalmente o esquema, registram somente as partes mais relevantes (PEREIRA; SILVA, 2007).

Além disso, em relação aos aspectos estéticos, o esquema é produzido em forma de tópicos objetivos e/ou de sentenças sucintas, visto que, por meio dele, é possível reconhecer rapidamente as principais partes do texto-base; já o fichamento resulta da extração de fragmentos de um texto lido, e o resumo, da sumarização. O resumo é, ainda, escrito em prosa e consiste em condensar o assunto de um texto, formando parágrafos com sentido completo, enquanto que o esquema apenas indica os tópicos mais importantes.

A principal vantagem de um esquema é, dessa forma, facilitar a fixação do conteúdo e sua recapitulação posteriormente. Ele ajuda também a evitar repetições ou omissões ao longo do desenvolvimento de um trabalho acadêmico, seja este uma monografia, dissertação, tese, relatório, etc., justamente porque expõe, de maneira lógica e sistemática, as principais informações do assunto de um texto (LAKATOS; MARCONI, 2003, p. 260).

Lakatos e Marconi (2003), em seu capítulo sobre leitura, destacam a importância de se captar a ideia principal de cada parágrafo do texto, separando-a de partes menos relevantes. Para tal, as autoras recomendam, após a realização de várias leituras, o uso do recurso de sublinhar essas partes, com o intuito de destacá-las. Em seguida, propõem que se elabore, a partir das partes destacadas no texto, um esquema, o qual deve respeitar:

a hierarquia emanada do fato de que, em cada frase, a idéia expressa pode ser condensada em palavras-chave; em um parágrafo, a idéia principal é geralmente expressa numa frase-mestra; e, finalmente, na exposição, a sucessão das principais idéias concretiza-se nos parágrafos-chave (LAKATOS; MARCONI, 2003, p. 25). 
Desse modo, a elaboração de um esquema se baseia na hierarquia das palavras, frases e parágrafos-chave, os quais devem ter ligação com as ideias do texto. Portanto, como estamos adotando a noção de esquema como um "instrumento" por meio do qual se pode sumarizar a leitura de um assunto ou texto lido (PEREIRA; SILVA, 2007; DUARTE, 2012), é importante que um esquema tenha: tópicos sucintos (organizados por numeração ou marcadores); hierarquização de ideias presentes no texto-base; paráfrases.

Quanto à representação gráfica do esquema, esta pode ser feita de várias formas, por isso sua classificação abrange vários tipos, descritos a seguir (DIONISIO, 2013):

a) esquema de setas ou flechas: caracteriza-se pela presença de setas e pode assumir a forma linear, horizontal ou vertical, piramidal, circular ou, ainda, retangular;

b) esquema de chavetas: contém o sinal gráfico chaves em forma linear-horizontal, cuja função é concatenar ideias primárias a secundárias e assim sucessivamente;

c) esquema de subordinação: possui dois subtipos: o numerado e o de letras. O numerado configura-se por meio da enumeração de ideias, e o que diferencia as ideias principais das complementares são as sequências numéricas, as quais devem ser de um tipo para as ideias principais e de outro tipo para as ideias complementares. O subtipo de letras se assemelha ao numerado e segue a mesma lógica hierárquica deste, a única coisa que os discrimina são as letras, utilizadas no lugar dos números;

d) esquema de retângulos: constitui-se por meio de retângulos ligados por linhas e sua organização pode ser linear, horizontal ou vertical, piramidal ou retangular;

e) esquema de ideias: tipo mais confundido com o diagrama, possui uma ideia central e dela saem diversas linhas que têm a função de ligar a ideia fundamental às subordinadas, apresentando uma hierarquia;

f) esquema misto: apresenta dois ou mais tipos de esquema.

Notamos, pois, que a elaboração de um esquema se baseia, principalmente, na hierarquia das palavras, frases e parágrafos-chave, os quais devem ter ligação com as ideias do texto (PEREIRA; SILVA, 2007; DUARTE, 2012). Nesse sentido, tendo em vista suas especificidades, bem como as características relacionadas a sua funcionalidade, podemos definir o esquema como um gênero textual. Nessa perspectiva, Bronckart aponta, ainda, que "conhecer um gênero de texto também é conhecer suas condições de uso, sua pertinência, sua eficácia ou, de forma mais geral, sua adequação em relação às características desse contexto social” (BRONCKART, 1999, p. 48). Portanto, se faz necessário conhecer os esquemas constitutivos do corpus deste trabalho, bem como sua estruturação e planificação textual, além das suas condições de produção.

\section{Embasamento teórico: os parâmetros do contexto de produção}

Para a análise dos dados, o presente artigo se baseou nos postulados teóricos do ISD em relação aos parâmetros do contexto físico e sociossubjetivo de produção. $\mathrm{Na}$ abordagem dessa corrente, o estudo da língua deve se pautar nas diferentes ações de linguagem. A partir dessa perspectiva, Bronckart (1999) analisa a linguagem como prática social, com inspiração em Volochinov (2009), considerando os aspectos referentes às condições de produção dos enunciados, à enunciação e ao contexto.

Em síntese, o ISD parte do pressuposto de que toda atividade de linguagem é coletiva e social, de forma que é no agir comunicativo que compartilhamos os conhecimentos humanos e confirmamos efetivamente as avaliações dos mundos objetivo, social e subjetivo, isto é, o mundo objetivo das coisas, o mundo social das normas e instituições e o mundo subjetivo das vivências e dos sentimentos (BRONCKART, 2008). Todas essas implicações 
auxiliam na compreensão das influências que as representações sociais exercem sobre o agente-produtor no processo de produção textual.

Nesse sentido, no momento de elaboração de um texto, representações sobre esses mundos são mobilizadas pelo agente e essa mobilização pode ser efetuada em dois sentidos diferentes: de um lado, o contexto de produção (a situação de interação/comunicação, referente ao mundo físico e ao mundo sociossubjetivo); e, de outro lado, o conteúdo temático (os temas verbalizados no texto). Desse modo, em relação ao contexto de produção, Bronckart (1999, p. 93) o define como o "conjunto dos parâmetros que podem exercer uma influência sobre a forma como um texto é organizado".

O primeiro parâmetro se refere ao mundo físico, o qual estabelece que todo texto é resultado de um comportamento verbal concreto, este desenvolvido por um agente dentro de um espaço e de um tempo. Nesse primeiro parâmetro, encontram-se aspectos relacionados ao lugar de produção (lugar físico no qual o texto é produzido); momento de produção (extensão do tempo durante a qual o texto é produzido); emissor (produtor/locutor, pessoa que produz fisicamente o texto na modalidade oral ou escrita); e receptor (quem percebe ou recebe concretamente o texto) (BRONCKART, 1999).

Já o segundo parâmetro do contexto de produção se refere ao mundo sociossubjetivo, estabelecendo que todo texto está inserido no quadro de uma formação social, mais especificamente, no quadro de uma forma de interação comunicativa que implica o mundo social e o subjetivo. Nesse parâmetro, encontram-se: lugar social (quadro da formação social, instituição ou modo de interação em que o texto é produzido); posição social do emissor/enunciador (papel social desempenhado pelo emissor/enunciador na interação); posição social do receptor/destinatário (papel social atribuído ao receptor/destinatário do texto); e objetivo da interação (efeito que o emissor/enunciador pretende causar no destinatário com o seu texto) (BRONCKART, 1999).

\section{Análise dos dados: esquemas de recepção e de construção textual}

O corpus desta pesquisa é constituído de 19 esquemas, dos quais 3 foram elaborados para a produção futura de um relatório, ou seja, para uma construção textual, e 16 são esquemas de leitura, ou de recepção, cujo texto-fonte é o resumo de um relatório de pesquisa. Uma vez que os aspectos do contexto de produção, físico e sociossubjetivo, desses textos circundam toda e qualquer atividade e incidem diretamente na ação de um indivíduo, além de influenciarem as condições em que o texto é organizado, apresentamos, no quadro 1 a seguir, os parâmetros das condições de produção dos esquemas em análise.

\begin{tabular}{|c|c|c|}
\hline \multirow{4}{*}{$\begin{array}{l}\text { Parâmetros } \\
\text { objetivos }\end{array}$} & $\begin{array}{l}\text { Lugar de } \\
\text { produção }\end{array}$ & Auditório da Universidade Federal da Paraíba. \\
\hline & $\begin{array}{l}\text { Momento de } \\
\text { produção }\end{array}$ & $\begin{array}{l}\text { Durante a ocorrência das oficinas sobre Esquemas, } \\
\text { realizadas no V Workshop de Letramento Acadêmico. }\end{array}$ \\
\hline & Emissores & $\begin{array}{l}\text { Alunos graduados e graduandos oriundos de cursos de } \\
\text { diversas áreas, em sua maioria de Letras. }\end{array}$ \\
\hline & Receptores & Ministrantes das oficinas. \\
\hline \multirow{2}{*}{$\begin{array}{l}\text { Parâmetros } \\
\text { sociossubjetivos }\end{array}$} & Lugar social & $\begin{array}{l}\text { Ambiente acadêmico. Instituição pública federal de ensino } \\
\text { superior. }\end{array}$ \\
\hline & $\begin{array}{l}\text { Posição social } \\
\text { dos emissores }\end{array}$ & $\begin{array}{l}\text { Professores e alunos graduados e graduandos de diversas } \\
\text { áreas, em sua maioria de Letras. }\end{array}$ \\
\hline
\end{tabular}




\begin{tabular}{|c|c|l|}
\hline & $\begin{array}{l}\text { Posição social } \\
\text { dos receptores }\end{array}$ & $\begin{array}{l}\text { Alunos do mestrado e doutorado em Linguística, } \\
\text { participantes do ATA. }\end{array}$ \\
\cline { 2 - 4 } Objetivo & $\begin{array}{l}\text { Enquanto esquema de recepção, o objetivo é sintetizar as } \\
\text { ideias centrais de um texto, e como um gênero a priori, é } \\
\text { esboçar o esqueleto de um texto a ser redigido. }\end{array}$ \\
\cline { 2 - 3 } & $\begin{array}{l}\text { Paráfrase objetiva das ideias centrais de um resumo de } \\
\text { relatório ou mapeamento de ideias centrais para a } \\
\text { produção posterior de um relatório, a partir de uma } \\
\text { teterminada organização gráfica. }\end{array}$ \\
\hline
\end{tabular}

Quadro 1 - Contexto de produção físico e sociossubjetivo.

Dentre os três esquemas elaborados para a produção futura de um relatório, ou seja, enquanto um gênero a priori, os emissores utilizaram a organização gráfica do gênero classificado como esquema de subordinação numerado, em atendimento ao proposto na atividade durante a oficina: "Esboce um esquema de subordinação numerado que apresente os elementos textuais de um relatório (cf. ABNT NBR 10719, 2011)". Vejamos esses esquemas a seguir:

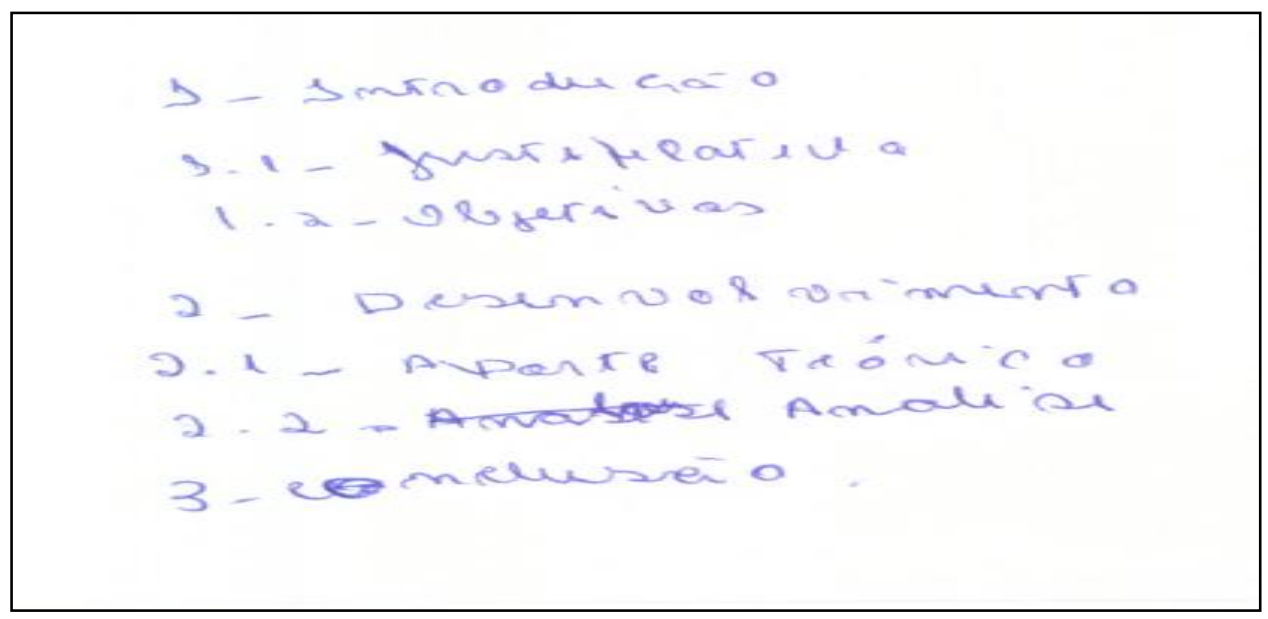

Figura 1 - Esquema de subordinação 1.

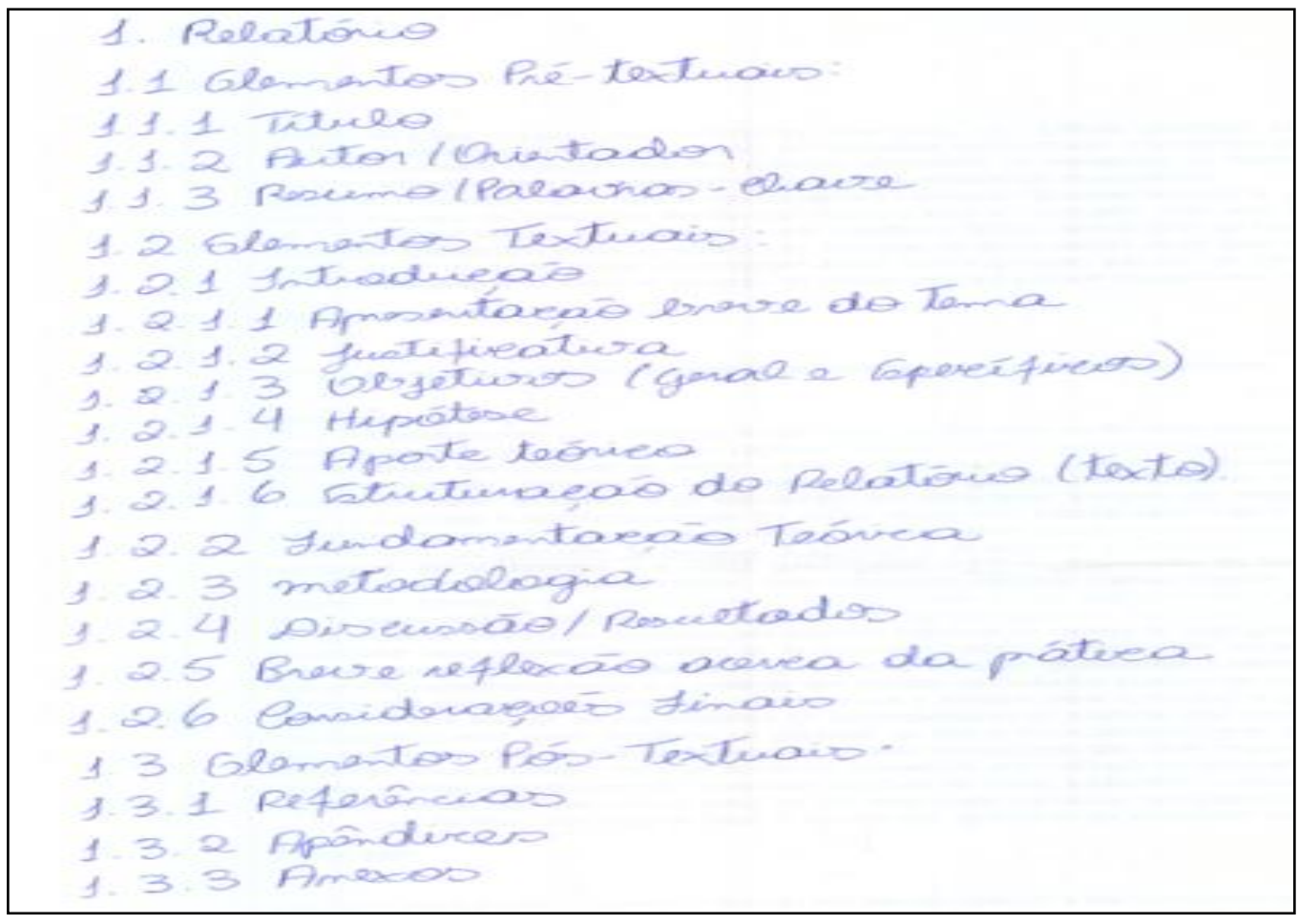


Figura 2 - Esquema de subordinação 2.

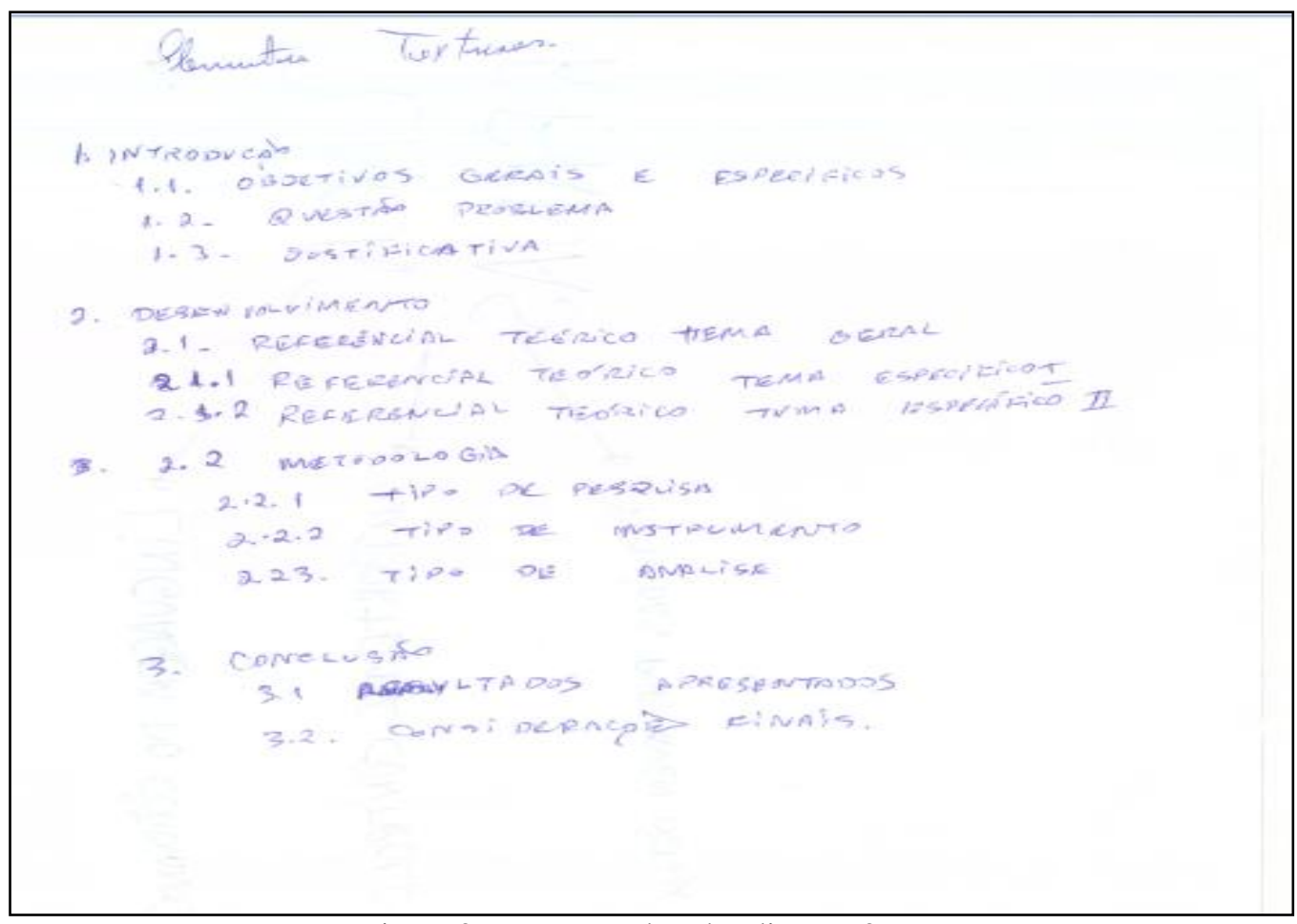

Figura 3 - Esquema de subordinação 3.

Embora todos os emissores tenham atendido ao gênero esquema, podemos observar que há singularidades importantes quanto ao conteúdo temático e à arquitetura textual de cada texto produzido, o que configura, inclusive, uma das propriedades dos gêneros discursivos, conforme Bakhtin (2000): o estilo verbal de cada autor. Assim, o esquema 1, em relação aos demais, é o mais sintético, talvez pelo fato de atender ao direcionamento de mapear apenas os elementos textuais de um relatório, porém é o que mais se adéqua ao solicitado no contexto de produção do gênero, apresentando introdução, desenvolvimento e conclusão.

Já o esquema 2, embora destaque, no topo do texto, tratar-se dos "Elementos textuais", verificamos que é mais detalhado, entretanto, seu conteúdo temático nos incita a interpretar que se refere a um esquema para a produção de um projeto e não de um relatório, tendo em vista que, na introdução, é destacado o elemento "1.2 Questão Problema", o qual, normalmente, constitui o conteúdo temático do contexto de produção de um projeto; e, ainda, pelos subtópicos do desenvolvimento (tópico 2), que se distribuem em "2.1 Referencial Teórico Tema Geral", o qual, por sua vez, subdivide-se em "2.1.1 Referencial Teórico Tema Específico I" e "2.1.2 Referencial Teórico Tema Específico II; e em "2.2 Metodologia", no qual se sobressaem os elementos pertencentes à metodologia científica do esboço de um projeto (tipo de pesquisa, tipo de instrumento e tipo de análise).

Por fim, o esquema 3 é o mais extenso, visto que o autor preocupa-se em esboçar o passo a passo para a elaboração do gênero relatório, mapeando não apenas os elementos textuais, mas também os elementos pré e pós-textuais. Além disso, reserva o primeiro tópico com o título do gênero a ser produzido, não deixando dúvidas de que se trata do esquema $a$ priori de um relatório. Analisando os elementos textuais, que é nosso foco de estudo, observamos que, embora o autor tenha colocado um tópico na introdução referente à hipótese (item 1.2.1.4), isso não o caracteriza como um esquema para a construção textual de um projeto, pois compreendemos estar mais relacionado à síntese dos resultados do relatório. Ainda, o subtópico "1.2.5 Breve reflexão acerca da prática" nos leva a deduzir que se trata de 
um esquema para elaborar um relatório de estágio, levando em conta o que foi apresentado no Workshop em relação às características e tipos de relatórios. Um fato interessante, também, no esquema 3 , diz respeito à sua estrutura composicional, em que o autor demarca, com o uso da pontuação, as partes do relatório, colocando o sinal dos dois-pontos nos itens 1.1 e 1.2 e ponto final no item 1.3.

Em síntese, depreendemos que os participantes da oficina, mesmo fugindo do conteúdo temático do contexto de produção do esquema enquanto um gênero a priori de um relatório e apresentando estilo e estrutura composicional singulares, compreenderam a função sociocomunicativa desse gênero. Portanto, observamos a possibilidade de didatização do esquema e a sua relevância para uma melhor organização das ideias, o que faz dele uma rica ferramenta que precisa ser trabalhada e produzida em sala de aula, tendo em vista as dificuldades ainda apresentadas pelos alunos, as quais, muitas vezes, são ignoradas pelos professores que, ingenuamente, presumem que os estudantes já têm total domínio desse gênero.

Em relação aos 16 esquemas de leitura/recepção, o texto-fonte que os originou é o resumo de um relatório final de pesquisa do Programa Institucional de Bolsas de Iniciação Científica (PIBIC), da UFPB. O resumo se volta para o discurso do cotidiano, a partir de placas urbanas, e seu objetivo é compreender como ocorre a governamentabilidade e os contextos dos dizeres nos espaços urbanos da cidade de João Pessoa. Conforme consta no resumo, o resultado da pesquisa mostrou que as placas distribuídas por esses espaços urbanos apresentam-se como suporte de materialização de relações de poder e, ainda, que o governo tem a responsabilidade de organizar, controlar e disciplinar a vida dos indivíduos e os espaços que eles ocupam. Dos 16 esquemas produzidos, escolhemos três, um que atendeu às características e funções do gênero, outro que as compreendeu superficialmente e outro que não obedeceu ao que foi proposto, como podemos ver a seguir.

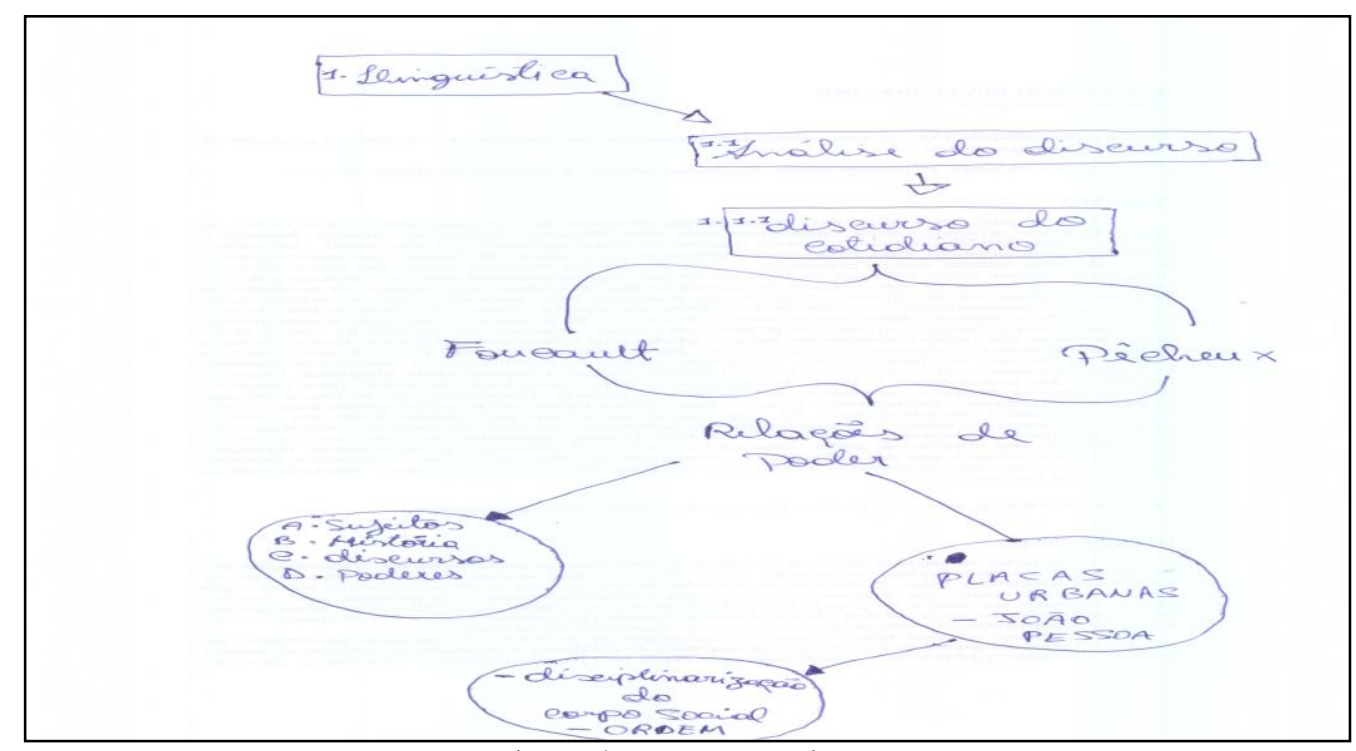

Figura 4 - Esquema misto.

Percebemos que o texto representado na figura 4 se trata de um esquema misto por apresentar diversidade em sua estutura composicional e conteúdo temático (retângulo, ideias, setas, chaves, letras e números). No entanto, considerando que, independentemente da organização gráfica, deve-se partir da ideia primária para a secundária e sintetizar as ideias centrais do texto-fonte, o esquema não demonstra remeter a um resumo de um artigo, pois não se preocupa em colocar as partes constituintes de tal gênero esquematizado (objetivo, 
justificativa, metodologia, fundamentação teórica e resultados), diferentemente do esquema da figura 5 a seguir:

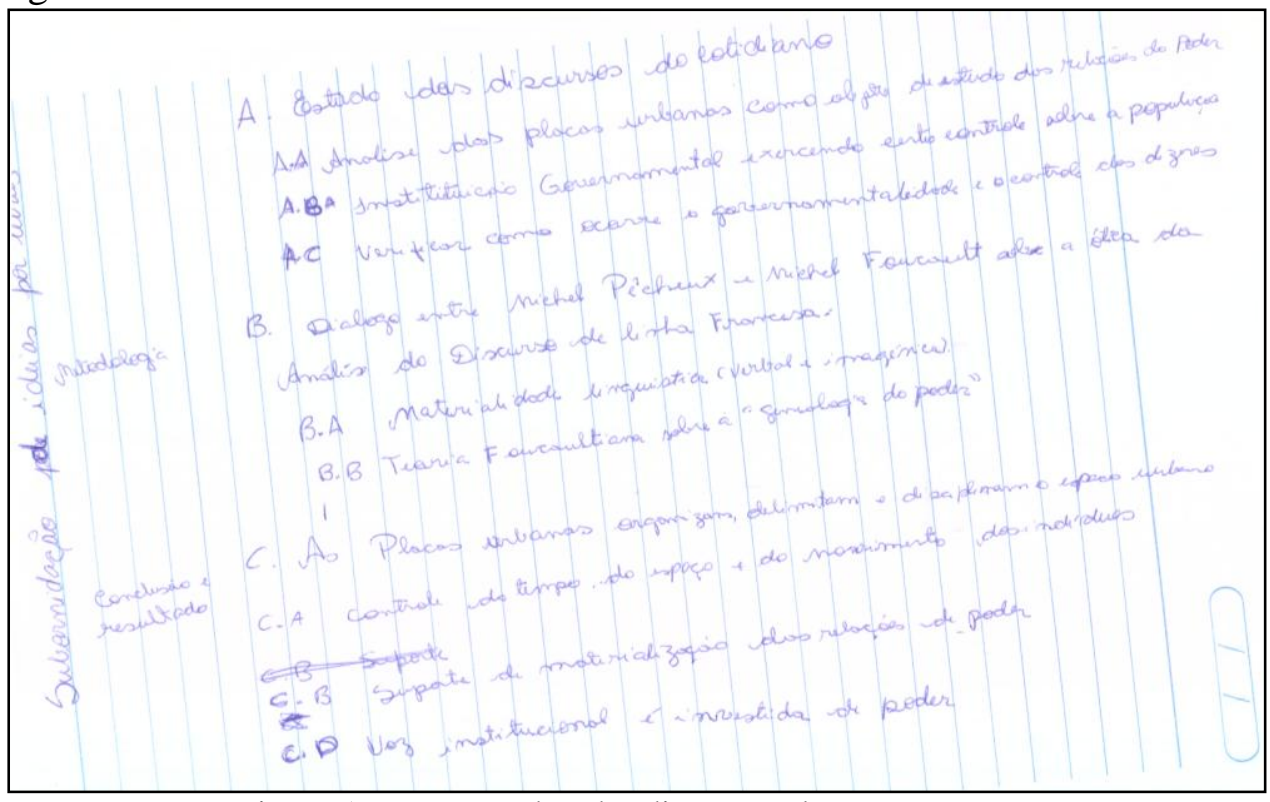

Figura 5 - Esquema de subordinção por letras.

A organização gráfica do texto da figura 5 atende ao tipo classificado como esquema de subordinação por letras, mas notamos que o autor sente necessidade de destacar a que se referem os tópicos, colocando tais informações fora da estrutura composicional do esquema, mais precisamente na lateral do texto (metodologia, conclusão e resultados), as quais poderiam constituir a arquitetura textual e remeter ao texto-fonte. Vejamos outro exemplo:

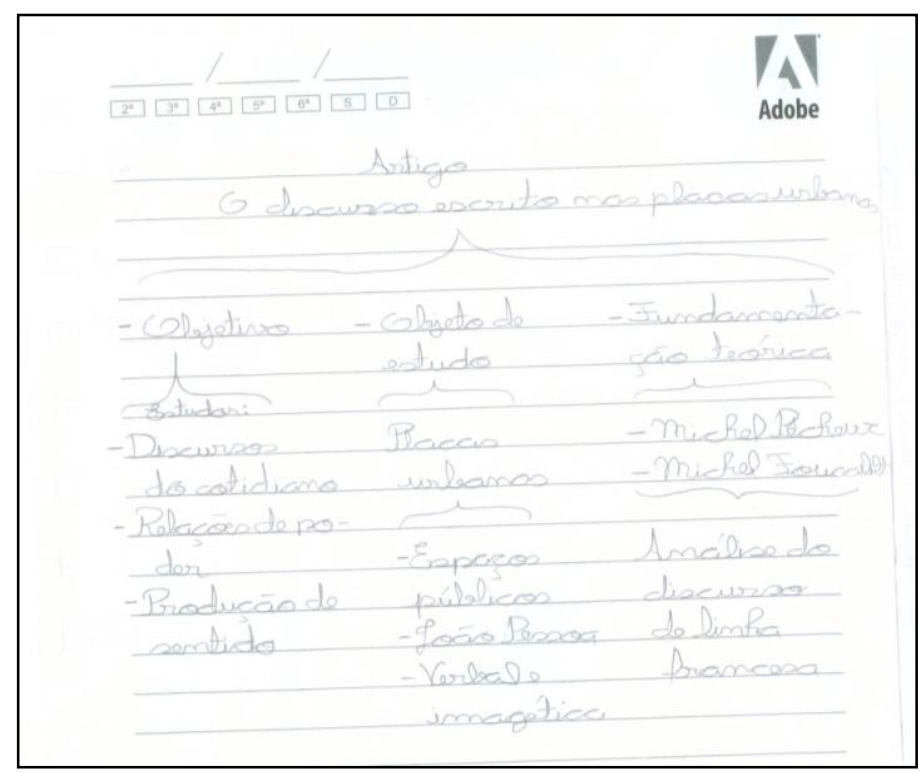

Figura 6 - Esquema de chavetas.

O esquema da figura 6 se classifica pelo tipo chavetas, visto que o autor usa chaves para hierarquizar as ideias do texto-fonte. Não há referência, mas no topo colocou-se "Artigo", fazendo menção ao texto esquematizado. O autor elenca as partes essenciais do resumo e demonstra ter compreendido a função do gênero esquema, já que o objetivo do texto-fonte é sintetizar as partes de um artigo (objetivo, justificativa, metodologia, fundamentação teórica e resultados). Nesse esquema, o grupo responsável por sua elaboração 
não apontou a metodologia nem o resultado, embora estivesse explicitado no texto-fonte. Assim, esse esquema é o que mais se adéqua ao protótipo do gênero, conseguindo respeitar a hierarquia do texto-fonte e condensando as ideias principais.

Em suma, após a análise dos esquemas, percebemos que os participantes da oficina conseguiram compreender a função do gênero esquema como uma forma de otimizar o tempo e registrar linguisticamente o conteúdo de um texto lido, mesmo que alguns aspectos do textofonte, como metodologia e resultados, por exemplo, não tenham sido mencionados nas produções. Percebemos, assim, que o esquema pode ser elaborado a partir de um gênero já existente (no nosso caso, o resumo), como também pode ser o gênero a priori para a construção de um outro gênero textual (no contexto em tela, o relatório).

\section{Conclusão}

O presente artigo buscou discutir sobre o gênero esquema como facilitador na recepção e construção de outros gêneros no âmbito da universidade. Os exemplos apresentados remeteram aos diversos tipos de esquema que cada grupo produziu de acordo com suas motivações e interiorização do conteúdo. No entanto, mesmo os participantes não seguindo totalmente o contexto de produção do esquema - estilo, estrutura e função sociocomunicativa, ficou compreendida a possibilidade de didatizar o gênero em questão. A partir do que foi apresentado neste trabalho, podemos concluir que o esquema, por seu caráter auxiliador, favorece a aprendizagem , uma vez que as ideias principais , representadas pelas palavras-chave, fazem com que haja uma visualização geral do assunto . O esquema é, ainda, uma estratégia de leitura , visto ser um procedimento que ajuda no entendimento do texto Pode, também, ser considerado um gênero simples, na maioria das vezes, em relação à sua estrutura, no entanto, ele exige uma leitura atenta, pois as ideias mais significativas devem estar em destaque, enquanto que ideias secundárias devem estar subordinadas a esta.

Além disso, o esquema possibilitou uma sintetização das ideias principais do resumo de um relatório ou, como um gênero a priori, a construção de um relatório futuro, por meio do qual se pode adquirir uma grande quantidade de informações. Produzir um esquema é uma tarefa árdua, tendo em vista que o leitor precisa compreender bem o conteúdo para transformá-lo em ideias mestres ou saber o que irá produzir futuramente, a fim de não omitir uma informação importante na construção do seu texto. Nessa perspectiva, acreditamos, ainda, que as pesquisas no campo da Linguística Aplicada contribuem para um melhor desenvolvimento do processo de ensino-aprendizagem, pois, ao analisarmos possibilidades de trabalhos com o gênero esquema, possibilitamos mostrar não apenas as características deste enquanto gênero, mas também o seu uso prático enquanto ferramenta didática.

\section{Referências}

BAKHTIN, Mikhail. Estética da criação verbal. Tradução da versão francesa: Maria Ermantina Galvão. 3. ed. São Paulo: Martins Fontes, 2000.

BRONCKART, Jean-Paul. Atividade de linguagem, textos e discurso: por um interacionismo sócio-discursivo. Tradução: Anna Rachel Machado. São Paulo: Educ, 1999.

DUARTE, Nayara Araújo. Esquema. In: SILVA, Elizabeth Maria da (Org.). Professora, como é que se faz? Campina Grande: Bagagem, 2012. p. 27-42. 
LAKATOS, Eva Maria; MARCONI, Marina de Andrade. Fundamentos de metodologia científica. 5. ed. São Paulo: Atlas, 2003.

PEREIRA, Bruno Alves; SILVA, Williany Miranda da. O gênero esquema no evento aula: funcionalidade e repercussões para o processo de ensino/aprendizagem. IV Simpósio Internacional de Estudos de Gêneros Textuais (SIGET), 2007, Santa Catarina. Anais... Santa Catarina: Universidade do Sul de Santa Catarina, 2007, p. 756-766.

PEREIRA, Regina Celi Mendes; LEITÃO, Poliana Dayse Vasconcelos Leitão (Orgs.). Ateliê de letras: projetos no tear. João Pessoa: Ideia, 2017.

VOLOCHINOV, Valentin. Marxismo e filosofia da linguagem. 16. ed. São Paulo: Editora Hucitec, 2009. 